\title{
WIND TURBINE CONTROL SYSTEM: A NEWS ALGORITHM IN THE CASE OF CONSTANT SPEED OPERATION
}

\author{
Hacene BENKHOULA*, Mohamed badreddine BENABDELLA ${ }^{* *}$, Hamid BOUZEBOUDJA*** \\ *Electrotechnical Department, Faculty of Electrical Engineering, USTO, \\ B.P 1505 El M'naouar, Oran, Algeria, Tel.: 213 672601682, E-mail: belharche@gmail.com \\ ${ }^{* *}$ Electrotechnical Department, Faculty of Electrical Engineering, USTO, \\ B.P 1505 El M'naouar, Oran, Algeria, Tel.: 213 552535506, E-mail: benabdallah22@yahoo.fr \\ ${ }^{* * *}$ Electrotechnical Department, Faculty of Electrical Engineering, USTO, \\ B.P 1505 El M’naouar, Oran, Algeria, Tel.: 213 673372018, E-mail: hbouzeboudja@yahoo.fr
}

\begin{abstract}
The purpose of this study is to present various wind turbine control systems for different objectives according the wind speed as maximum wind power tracking, constant speed operation and constant power generation, which we present a news algorithm in the case of constant speed operation, the operating area at a constant speed is a intermediate control allow a smooth transition between the two other control. The modeling of wind turbine is presented.Then two different control systems are detailed and evaluated using Matlab/ Simulink softwares.
\end{abstract}

Keywords: modelling, control system, wind

\section{INTRODUCTION}

At this moment in time, wind power is set to become one of the major energy resources because it is a clean energy source. Also, it is one of the available nontraditional energy-giving [1].

The wind is a random variable difficult to measure difficult to master, for this, Researchers developed a mathematical algorithms enable to extract the maximum power of wind.

Today, the variable speed wind energy conversion system (WECS)are continuously increasing their market share, because it is possible to track the changes in wind speed by adapting shaft speed, thus maintaining optimal energy generation [1].

In the recent years, most development in the field touched the MPPT algorithm and pitch control. But the intermediate control which the speed is controlled to be constant is not mentioned, the reference [6] presents a constant speed operation algorithm Unproven and unclear.

The purpose of this paper is to present various wind turbine control systems for different objectives as maximum wind power tracking and constant speed operation. Firstly, we present the wind turbine model, which has been designed to simulate the dynamics of the system from the turbine rotor where the kinetic wind energy is converted to the mechanical energy. In second parts, the different control system are described and compared with the help of simulations [4].

\section{WIND TURBINE MODELING}

The reference [6] developed a simulation model of wind turbine and compares its results with practice tests. The results presented showed the high reliability of the model.

\subsection{Turbine modelling}

The power of wind is proportional with the cube of the wind speed:

$P_{v}=\frac{\sigma}{2} \cdot S \cdot v^{3}$

Where: $\sigma$ - the air density, $S$ - the swept area of the turbine, $v-$ the wind velocity.

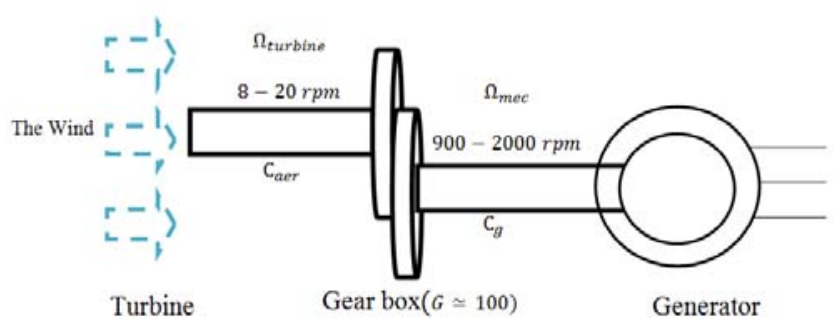

Fig. 1 Wind power generation system

The power coefficient $\left(C_{p}\right)$ represents the aerodynamic efficiency of the wind turbine. It depends on the tip speed ration $(\lambda)$ and the blade pitch angle $(\beta)$.

For the wind turbine used in the study, the following form has been derived from [6]:

$$
\begin{aligned}
& C_{P}(\lambda, \beta)=(0.5-0.167(\beta-2)) \sin \left[\frac{\pi(\lambda+0.1)}{18.5-0.3(\beta-2)}\right]- \\
& 0.00184(\lambda-3)(\beta-2)
\end{aligned}
$$

The tip-speed-ratio is defined as the ratio between the blade tip speed and the wind speed:

$\lambda=\frac{\Omega_{\text {turbine }} \cdot R}{v}$ 
Where: $R$ - the blade radius, $\Omega_{\text {turbine }}$ - the angular speed of the turbine.

The characteristic of the power aerodynamic efficiency is shown on Fig. 2.

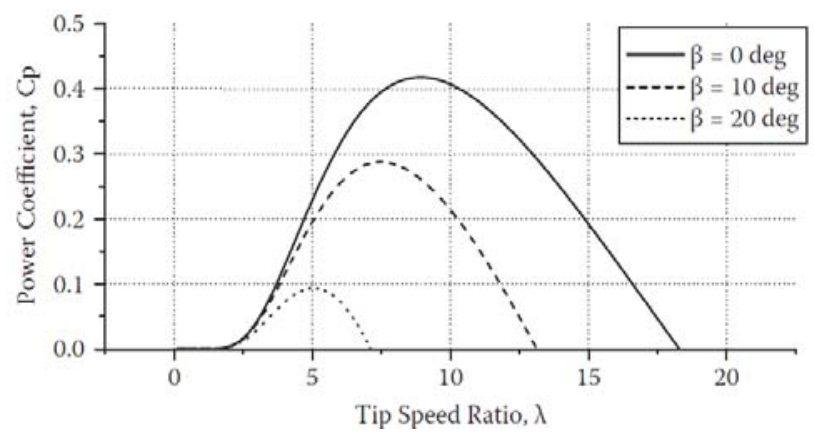

Fig. 2 Power aerodynamic efficiency versus tip speed ratio for a three bladed turbine

Using the $\mathrm{C}_{\mathrm{p}}$, aerodynamic power $\mathrm{P}_{\mathrm{aer}}$ is determined by:

$P_{\text {aer }}=C_{p} \frac{\rho \cdot \pi \cdot R^{2} \cdot v^{3}}{2}=\frac{1}{2} \frac{C_{p}}{\lambda^{3}} \rho \pi R \Omega_{m e c}^{3}$

The aerodynamic torque $\mathrm{C}_{\mathrm{aer}}$ is determined directly by:

$C_{\text {aer }}=\frac{P_{\text {aer }}}{\Omega_{\text {turbine }}}=C_{p} \cdot \frac{\rho . S \cdot v^{3}}{2} \frac{1}{\Omega_{\text {turbine }}}$

\subsection{Gearbox modeling}

The gearbox has the task to transfer the aerodynamically power from the slow rotating shaft to the fast rotating shaft, which derives the generator at the mechanical speed $\Omega_{\mathrm{mec}}$. It is mathematically described by the following equations:

$\mathrm{C}_{\mathrm{g}}=\frac{\mathrm{C}_{\mathrm{aer}}}{\mathrm{G}}, \Omega_{\text {turbine }}=\frac{\Omega_{\mathrm{mec}}}{\mathrm{G}}$

Where: $G$ - the gear ratio.

\subsection{Drive train modelling}

The drive train is composed of the mass corresponding to the large turbine rotor inertia representing the blade and the hub, and a small inertia representing the rotor mass of the generator. The proposed model only includes the turbine rotor because this part has the most significant influence on the power fluctuations. The acceleration is governed by the following equation [1]:

The drive train is constituted of the mass representing to the turbine rotor inertia $\left(J_{\text {turbine }}\right)$ including the blade and the hub, and an inertia $\left(J_{g}\right)$ representing the rotor mass of the generator. The total inertia $(J)$ is expressed by

$J=\frac{J_{\text {turbine }}}{G}+J_{g}$

The fundamental equation of dynamics can determine the evolution of the mechanical speed $\left(\Omega_{m e c}\right)$ from total mechanical torque $\left(C_{m e c}\right)$ applied to the rotor:
$\frac{J d \Omega_{m e c}}{d t}=C_{m e c}$

The total inertia (J), which appears onto the generator rotor, represent the acceleration time constant. Taking into account the electromagnetic torque $\left(\mathrm{C}_{\mathrm{em}}\right)$ and the viscous torque $\left(\mathrm{C}_{\mathrm{vis}}\right)$, the torque balance yields:

$C_{m e c}=C_{g}-C_{e m}-C_{v i s}$

The flexibility of the shaft is modeled as stiffness:

$C_{v i s}=f . \Omega_{m e c}$

The wind turbine model output is the aerodynamic torque applied on the gearbox. The inputs of the wind turbine model are the wind speed, the pitch angle and the turbine rotor speed.

The gearbox model transforms the mechanical speed and the aero dynamical torque respectively into the turbine rotor speed and the gearbox torque. The drive train model output is the mechanical speed and has two inputs: the gearbox torque and the electromechanical torque provided by the generator [4].As illustrated in Fig. 3 .

Fig. 3 shows that to control the turbine speed must be acting on two inputs: the blade pitch angle and the electromagnetic torque of the generator. The wind speed must be considered as a perturbation input for the system [4].

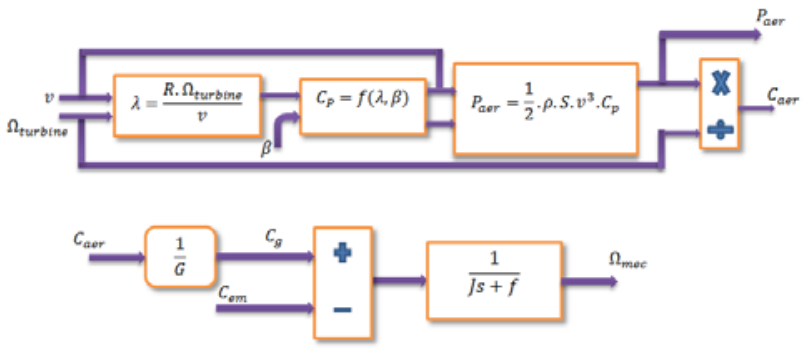

Fig. 3 Bloc diagram of wind turbine model

\section{POWER AND SPEED CONTROL ALGORITHMS OF THE WIND TURBINE}

Fig. 4, shows the turbine characteristics and the maximum power tracking characteristic of an example

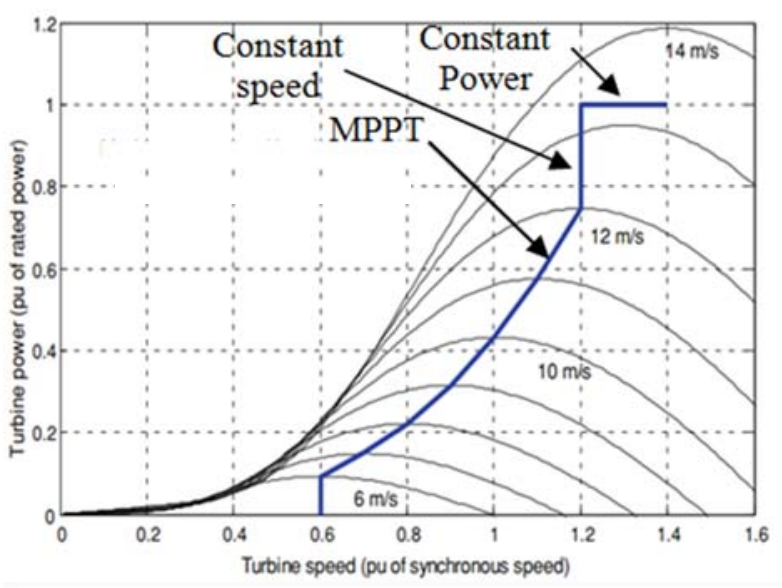

Fig. 4 Operating regions of the WECS 
DFIG based wind generator for wind speed ranging from 6 to $14 \mathrm{~m} / \mathrm{s}$ [3].

After the starting, a control strategy is designed to extract the Maximum power from the wind. In a third region, the mechanical speed is regulated to a value constant [7].

In the last region, a pitch control enables to limit the power to a maximum rated value.

\subsection{Maximum wind power extraction control:}

For a given wind speed the goal of the maximum power extraction is to regulate the turbine rotating speed to an optimal speed so that the maximum power can be captured from the wind [1].

It is observed that, for each wind speed, there exists a specific point in the output power versus rotating speed characteristic where the output power is maximized.

This technique consists in adjusting the electromagnetic torque of the generator in order to control the speed to the reference value. Other torques, which are applied to the shaft, are then considered as perturbation inputs [2].

According to (4), at a certain wind speed and certain pitch angle the available aerodynamic power depend on tip-speed ratio.

By replacing $\lambda=\lambda_{\text {opt }}$ and $\mathrm{C}_{\mathrm{P}}=\mathrm{C}_{\mathrm{P}}\left(\lambda_{\text {opt }}\right)$, one obtains the mechanical power reference for the second region of the power-wind speed curve:

$P_{\text {mec-ref }}=P_{M P P T}=k \Omega_{m e c}^{3}$

And hence, the electromagnetic torque reference is given by:

$C_{\text {em-ref }}=k_{o p t} \Omega_{m e c}^{2}$

Where

$k_{o p t}=\frac{C_{P}\left(\lambda_{\mathrm{opt}}\right)}{\lambda_{\text {opt }}^{3}} \frac{\rho \cdot \Pi \cdot R^{5}}{2} \cdot \frac{1}{G^{3}}$

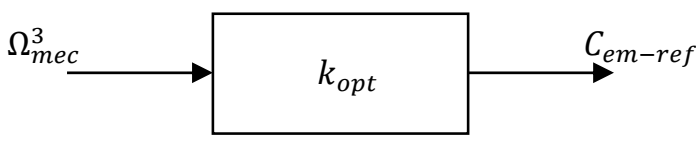

Fig. 5 MPPT controller

\subsection{Constant speed control}

In the case of a constant mechanical speed operation, the MPPT algorithm must be replaced by an algorithm for obtaining an operation at constant mechanical speed.

To reach this purpose, the tip-speed ratio should be adjusted to maintain a constant mechanical speed. We defined the tip-speed ratio by:

$\lambda=\frac{R \Omega_{m e c}}{G v}$

And

$\lambda v=\frac{R \Omega_{m e c}}{G}$
If the mechanical speed is constant (equal to $90 \%$ of rated mechanical speed) will be:

$\lambda v=\frac{90 \% R \Omega_{m e c}}{G}=K=c t s$

Where:

$K=\frac{90 \% R \Omega_{m e c}}{G}$

The tip-speed ratio which corresponds to a constant mechanical speed is expressed by:

$\lambda_{\Omega_{\text {mec-constant }}}=\frac{K}{v}$

\subsection{Pitch control}

At higher wind speed, wind power generation is limited at its rated power by pitch control. The pitch control will be activated either when mechanical wind power is larger than its rated value, or the mechanical speed is larger than its upper limit which is typically 1.2 p.u [2].

To reach this purpose, the power conversion Coefficient should be adjusted to maintain a constant power.

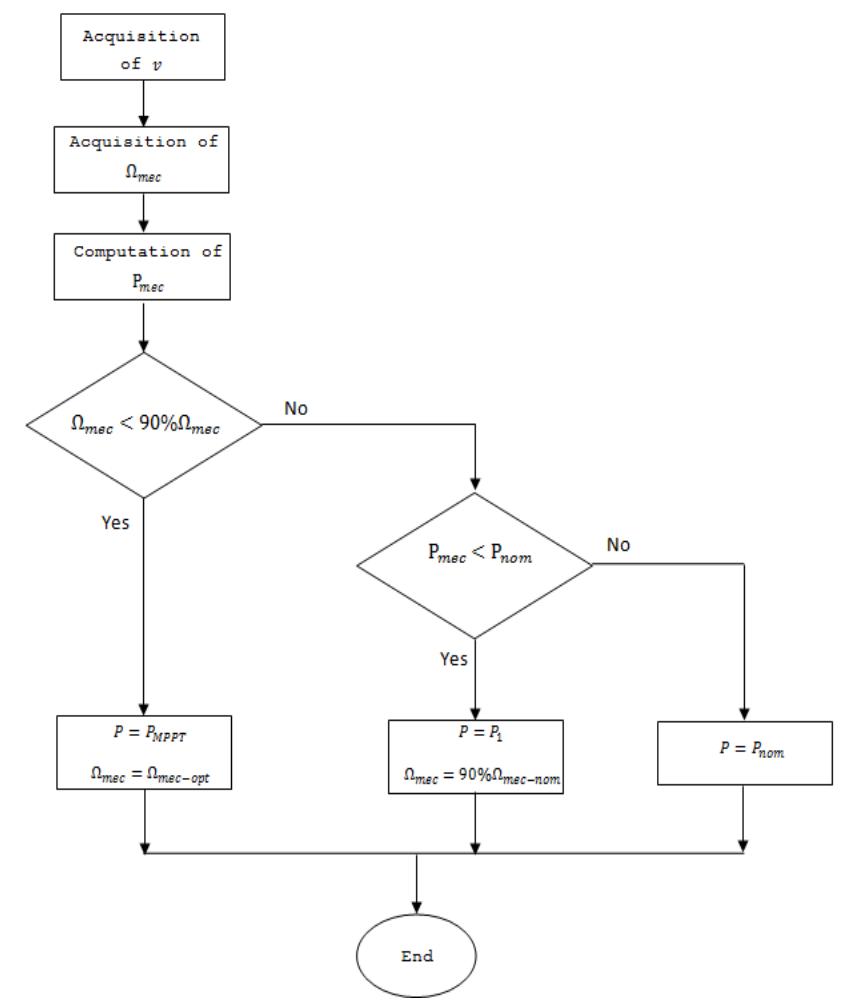

Fig. 6 Control algorithm of the wind turbine

The control structure has been simulated assuming an average wind profile about ( $8 \mathrm{~m} / \mathrm{s})$ (Fig. 7$)$.

The equation characterizing the wind is given by:

$v(t)=2 \sin (2.665 t)+2 \sin (0.147 t)+$ $0.2 \sin (3.6645 t)+8$

From the simulation results correspond to this control algorithm, the variations in the mechanical speed are 
adapted to the variation of the wind velocity. The aerodynamic power converted into electric power produced is fluctuating.

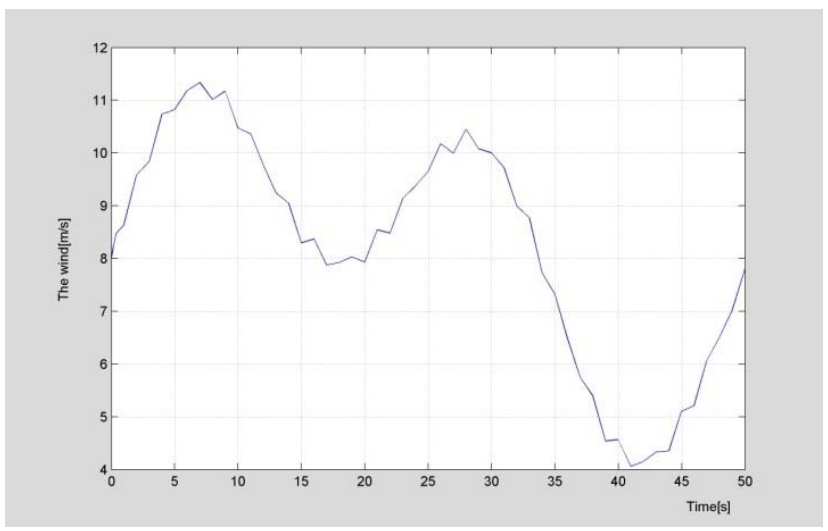

Fig. 7 The wind profile

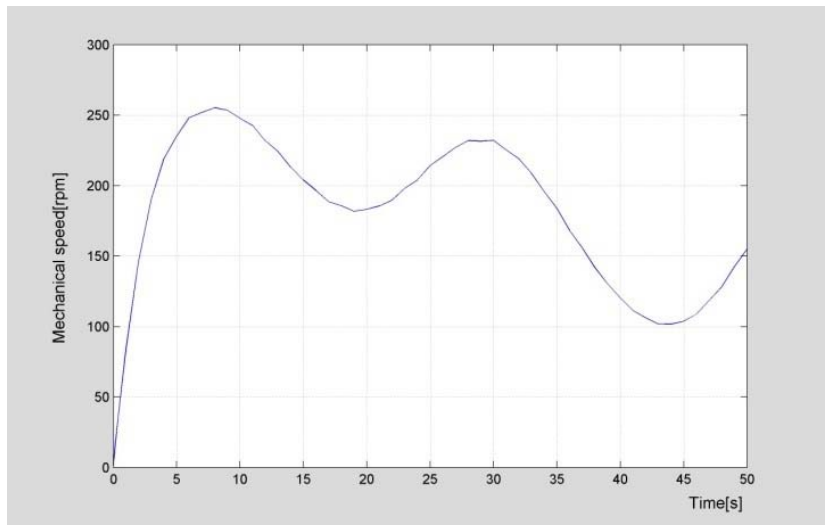

Fig. 8 Mechanical speed

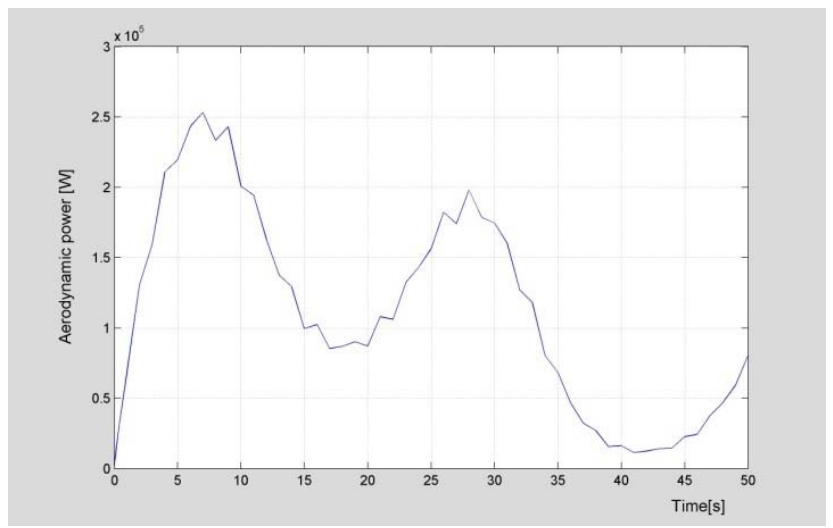

Fig. 9 Aerodynamic power

To validate the algorithm for a constant mechanical speed operation, we applied to the turbine an increasing wind profile up to $20 \mathrm{~m} / \mathrm{s}$, over a period of one hour (Fig. 10).

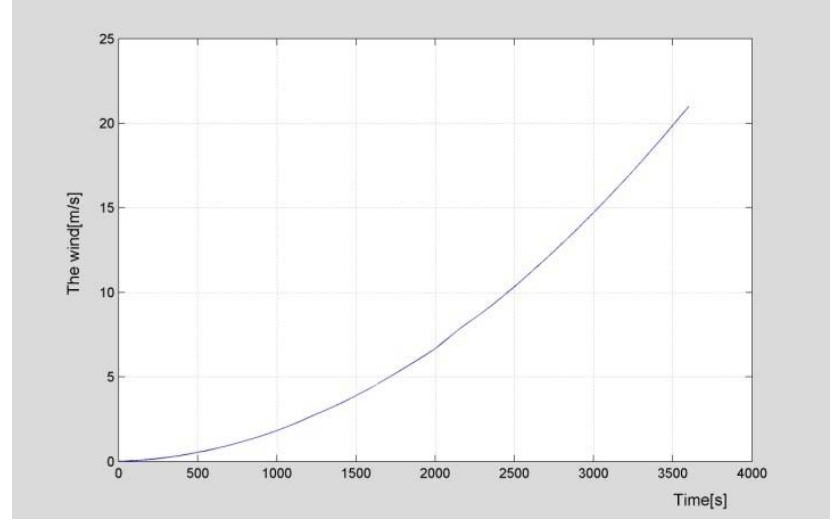

Fig. 10 The wind profile

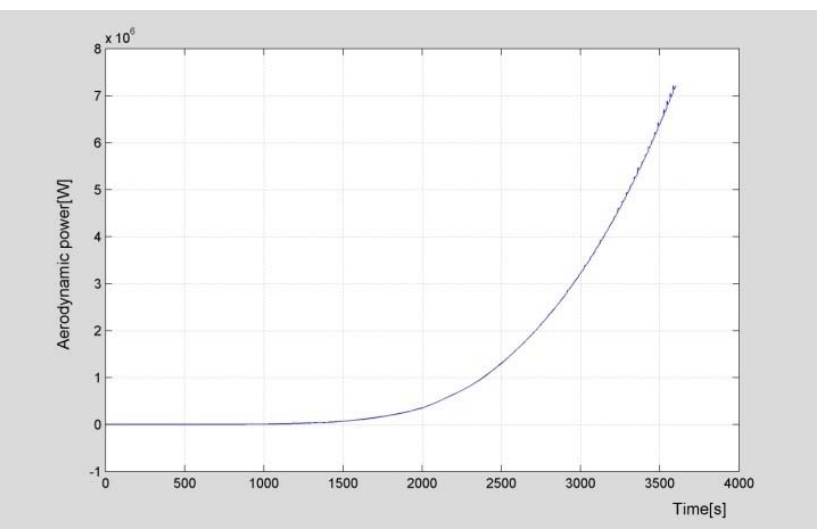

Fig. 11 Aerodynamic power

Fig. 12, represent the evolution of the mechanical speed, when the mechanical speed reaches $90 \%$ of its rated value, the control algorithm acts to make the mechanical speed constant.

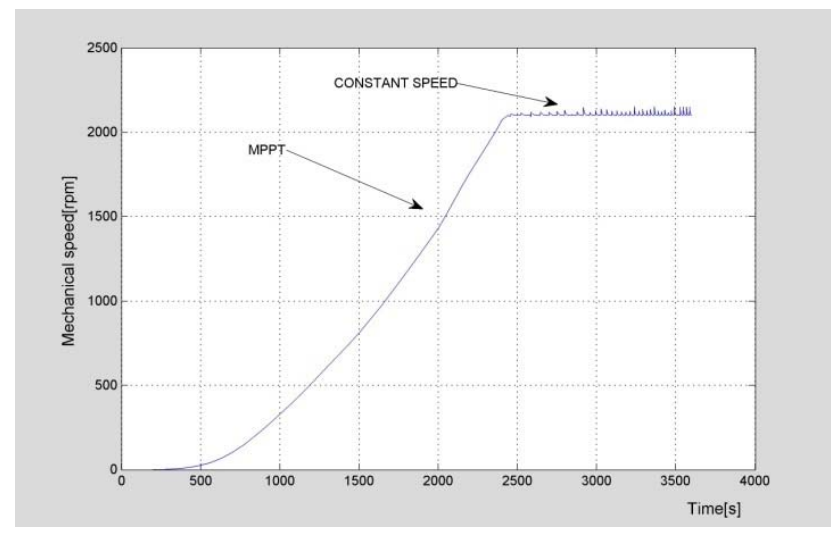

Fig. 12 Mechanical speed

The tip speed ratio is maintaining constant during MPPT operation, and changed according the variation of the wind speed, allowing to a constant mechanical speed operation (Fig. 13).

To maintain a constant speed, the efforts are focused on the torque and the electrical power is proportional the electromagnetic torque. 


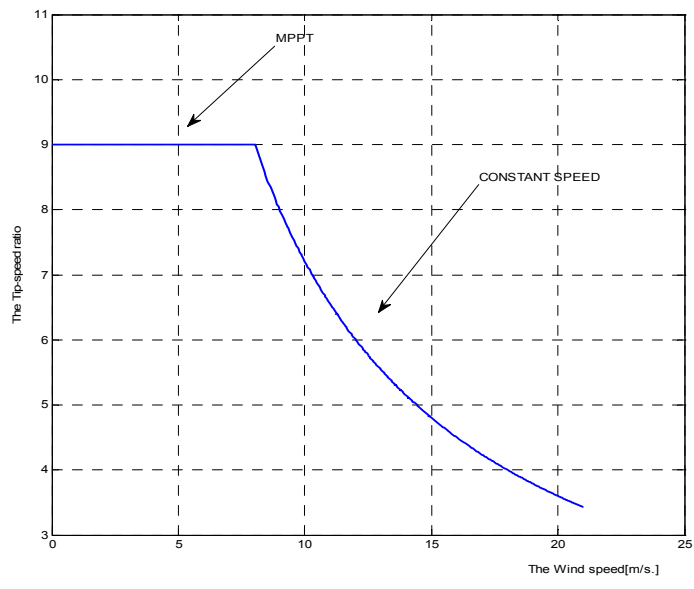

Fig. 13 The Tip-speed ratio v.s. wind speed

\section{CONCLUSIONS}

This present work is intended to study the conversion chain of wind energy into electricity, its control strategy for different objectives.

The operation of the subsystems constituting the conversion chain is described, modeled and evaluated using Matlab/Simulink. Which we present a new algorithm in the case of constant speed operation well demonstrate simple and efficient, the results presented showed the high reliability of the control algorithm. The variation of the speed ratio remains within the admissible limit. What makes this algorithm practical.

\section{REFERENCES}

[1] M. HASAN ALI: Energy systems, [online], 2012. Available: http://www.crcpress.com

[2] VITAL, V. - AYYNAR, R.: Grid Integration and Dynamic Impact of Wind Energy, [online], 2013. Available: http://www.wiley.com

[3] EL AIMANI, S.: Modelling and control structures for variable speed wind turbine, in Proc. 2011, ICMCS Multimedia Computing and Systems Conf., pp. 1-5.

[4] EL AIMANI, S.: Trends in grid integration of renewable. Case of doubly fed induction wind generation, in Proc. 2014, IRSEC Renewable and Sustainable Energy Conf., pp. 306-310.

[5] EL AIMANI, S.: Practical identification of a DFIG based wind generator model for grid assessment," in Proc. 2009, ICMCS '09 Multimedia Computing and Systems Conf., pp. 278-285.

[6] EL AIMANI, S.: Modelisation des different technologies d'éolienne integrees dans un réseau de moyenne tension, Ph.D. dissertation, Dept. Electrical. Eng., Ecol. Lille, 2004.

[7] LING, P.: Dynamic behavior of doubly fed induction generator wind turbines under three-phase voltage dips, 2009, IEEE 6th International Power Electronics and Motion Control Conference, 05/2009.
[8] MANSOUR, M. - MANSOURI, M. N. MIMOUNI, M. F.: Comparative study of fixed speed and variable speed wind generator with pitch angle control, International Conference on Communications Computing and Control Applications (CCCA), 2011.

[9] LI, S. - HASKEW, T. A. - WILLIAMS, K. A. SWATLOSKI, R. P.: Control of DFIG Wind Turbine with Direct-Current Vector Control Configuration, IEEE Transactions on Sustainable Energy, 2012.

[10] BRICE, B.: Sliding Mode Power Control of Variable Speed Wind Energy Conversion Systems, IEEE Transactions on Energy Conversion, 6/2008.

[11] MEHARRAR, A.: A variable speed wind generator maximum power tracking based on adaptative neuron fuzzy inference system, Expert Systems with Applications, 2011.

[12] BERKOUK, E. M.: Network Power Flow Control of Variable Speed Wind Turbine, 2007 International Conference on Power Engineering Energy and Electrical Drives, 04/2007.

Received November 26, 2015, accepted March 21, 2016

\section{BIOGRAPHIES}

Hacene Benkhoula was born on 15.05.1987. Received his Master degree in Electrical Engineering from University of Setif 1 in Algeria, in 2012. His thesis title was «practical implementation of control techniques for single phase AC chopper". His scientific research is focusing a practical methods based on mathematics algorithms for solving the integration problem of wind energy conversion system.

Mohamed badreddine Benabdallah was born on 22.12.1956 received the B. Eng. degree in Electrical Engineering from University of Sciences and Technology of Oran, Algeria, in 1982 and Magister of Engineering Science and $\mathrm{PhD}$ from the same University in 1996 and 2003 respectively. $\mathrm{He}$ is currently professor at the Electrotechnical Department, Faculty of Electrical Engineering at University of Sciences and Technology of Oran Algeria. His scientific research is focusing a diagnostic and modelling of electrical machine (polyphase).

Hamid Bouzeboudja was born on 04.03.1965. Received the B. Eng. degree in Electrical Engineering from University of Sciences and Technology of Oran Algeria, in 1989, He defended his "Magister" in the field of optimal power flow problems from the same University in 2005 and $\mathrm{PhD}$ from DJILLALI LIABES university of Sidi Bel-Abbes Algeria in 2006. He is currently professor at Electrotechnical Department Faculty of Electrical Engineering at University of Sciences and Technology of Oran Algeria. His scientific research is focusing a practical methods based on genetic algorithms for solving the economic dispatch problem of complex systems. 